\title{
Individualized Cancer Chemotherapy, Are We Ready for that Yet?
}

\author{
Da-Yong Lu' ${ }^{1 *}$, Ting-Ren $\mathrm{Lu}^{2}$ and Xue-Liang Chen ${ }^{3}$
}

${ }^{1}$ School of Life Sciences, Shanghai University, Shanghai 200444, PR China

${ }^{2}$ College of Science, Shanghai University, Shanghai 200444, PR China

${ }^{3}$ Department of Oncology and Thermotherapy, Central Hospital of Jing-An District, Shanghai, PR China

A major obstacle to control cancer growth and metastases in patients is the widespread inappropriate use of anticancer drugs. As increasing number and types of anticancer drugs developed, clinicians become more and more likely to misuse them in their practice. Present norm is to randomize and standardize chemotherapy in relation to the target organs or tumor origins. Because tumors can originate from a wide variety of different genetic backgrounds, most cancer cases have become unsuited to use "uniform" or "standardized" chemotherapy. Since no single drug or one combination has so far been found that is optimal for cancer of all origins, developing a good and clinically practical drug selection system is no less important than the discovery of new drugs.

Individualized cancer chemotherapy (ICC), which improves therapeutic quality by selecting and prescribing well-matched drugs and avoiding ineffective ones, has been attracting increasing attentions worldwide. However many debated issues are unresolved and many obstacles are remained in clinical practices.

\section{Amongst Different Types of ICC, Which of ICC Strategy is the Best?}

The individualized strategy was pioneered in drug sensitivity tests half a century ago [1-6]. Now, many new types of strategies have been emerging [6], including pharmacogenetics [7-9], pathogenic markeroriented therapy [6] and so on. Since we may not possibly use all of these strategies in one patient, amongst different types of ICC, which of ICC strategy is the best? Each of them has its own advantages and disadvantages. At present no one type of ICC strategies is obviously advantageous over the others. Also, no available ICC strategy has been well enough to significantly increase the patient's survival compared with conventional therapy. So we desperately need some magic moves to improve present ICC strategies or create new types of ICC strategies to integrate the advantages of all ICC types.

\section{How to Tighten our Budgets}

All the present ICC strategies need a lot of money to implement. It often worsens the financial and psychological conditions of cancer patients. So any improvements relating to simply the testing procedures or technical improvements are especially welcomed.

\section{More Understanding the Cancer Biology}

As our understanding about cancer is lacking, many steps relating to explain the clinical data can not be always straightforward. For example, response to chemotherapy is likely to be multigenic [9]. Inhibition of anticancer drugs against one cancer-related gene may not always result in good tumor inhibition and patient's survival. These drugs may same time trigger some other cancer-related processes or multidrug resistance genes. This is the difficulty problem in all present gene-related studies. So it is helpful to combine empirical and biomolecular theory in one ICC strategy.

In conclusion, we appeal for every cancer patient in the future to have his own unique chemotherapy trial based on consultation of pathogenic profiles and drug sensitivity testing data. Research and application of ICC will be encouraged by growing patient demands, scientific advances and medical ethics. But are we ready for that yet?

\section{References}

1. Black MM, Speer FD (1954) Further observations on the effects of cancer chemotherapeutic agents on the in vitro dehydrogenase activity of cancer tissue. J Natl Cancer Inst 14: 1147-1158.

2. Wright JC, Cobb JP, Gumport SL, Golomb FM, Safadi D (1957) Investigation of the relation between clinical and tissue-culture response to chemotherapeutic agents on human cancer. N Engl J Med 257: 1207-1211.

3. Bodegen AE, Kelton DE, Cobb WR, Esber HJ (1978) A rapid screening method for testing chemotherapeutic agents against human tumor xenograft. In: Houcheus DP, Ovejera AA, editors. Proceedings of the symposium on the use of athymic (nude) mice in cancer research. New York: Gustav Fischer Inc 231-250.

4. Hamburger AW, Salmon SE (1977) Primary bioassay of human tumor stem cells. Science 197: 461-463.

5. Salmon SE, Hamburger AW, Soehnlen B, Durie BG, Alberts DS, et al. (1978) Quantitation of differential sensitivity of human-tumor stem cells to anticancer drugs. N Engl J Med 298: 1321-1327.

6. Lu DY, Chen XL, Ding J (2006) Individualized cancer chemotherapy integrating drug sensitivity tests, pathological profile analysis and computational coordination-an effective strategy to improve clinical treatment. Med Hypotheses 66: 45-51.

7. Watters JW, McLeod HL (2003) Cancer pharmacogenomics: current and future applications. Biochim Biophys Acta 1603: 99-111.

8. Efferth T, Volm M (2005) Pharmacogenetics for individualized cancer chemotherapy. Pharmacol Ther 107: 155-176.

9. Huang RS, Ratain MJ (2009) Pharmacogenetics and pharmacogenomics of anticancer agents. CA Cancer J Clin 59: 42-55.

*Corresponding author: Da-Yong Lu, School of Life Sciences, Shanghai University, Shanghai 200444, PR China, E-mail: ludayong@sh163.net

Received February 28, 2012; Accepted March 01, 2012; Published March 03 2012

Citation: Lu DY, Lu TR, Chen XL (2012) Individualized Cancer Chemotherapy, Are We Ready for that Yet? Metabolomics 2:e113. doi:10.4172/2153-0769.1000e113

Copyright: @ 2012 Lu DY, et al. This is an open-access article distributed under the terms of the Creative Commons Attribution License, which permits unrestricted use, distribution, and reproduction in any medium, provided the original author and source are credited. 